\title{
Intelligent Knowledge Service System Based on Depression Monitoring of College Students
}

\author{
https://doi.org/10.3991/ijet.v14i12.10702 \\ Huina Yu, Guihong Zhang, Jiali Liu, Kai Li ${ }^{(凶)}$ \\ Zhejiang Chinese Medical University, Zhejiang, China \\ kaili@fudan.edu.cn
}

\begin{abstract}
The number of college students suffering from depression has increased in recent years. In order to help the college student administration departments understand students' psychological state of depression better and keep college students mentally healthy through mental health services, this paper studies an intelligent monitoring system for depression. Different from previous researches, this study, based on the cloud services platform, incorporates three indicators closely related to depression-sleeping, exercise and heart rate-into the monitoring database subsystem and establishes a relatively macroscopic intelligent knowledge service system for depression monitoring of college students. It uses the Mobile Material Link Device (MMLD) to collect data and information to monitor and analyze the changes in the depression status of college students dynamically, which also provides timely warnings and a chain of personalized intelligent knowledge services based on individuals' depression status.
\end{abstract}

Keywords-Depression monitoring, intelligent knowledge service system

\section{$1 \quad$ Introduction}

The college period is an important stage for the self-improvement and growth of college students, where psychological problems often appear among them, including depression. Not only does it have great impacts on the patients' physical and mental health, but also affects the living quality of the people around them [1]. At present, about $6 \%$ of the college students are suffering from depression, and this percentage is still on an obvious upward trend [2]. Therefore, it is of great importance to give early warning on depression. Currently, it is an important task for college student administrators to establish and improve the monitoring and warning mechanism for the depression status of college students. However, nowadays, the early warning about the depression of college students mainly relies on experts' experience-based judgment and lacks objective data support. And the management of depression relies on the individualized service of psychological experts, without a computerized and systematic management mode. The treatment and intervention of depression mainly focus on relaxation activities such as sports as suggested by experts, and the students with depression have no clear understanding of the causes and treatment principles of their 
depression. The traditional psychological treatment of depression lacks long-term and dynamic monitoring mechanism, which makes it impossible to understand the changes in the depression status of the students in real time. Therefore, it is very significant to construct an intelligent knowledge service system for depression monitoring of college students.

It has been found that the onset of depression is closely related to sleeping, exercise and heart rate [3-8]. Thus, this study includes these three indicators in the scope of depression monitoring and warning. Based on the knowledge base of the symptom self-rating scale (SCL-90) and the depression self-rating scale (SDS) and that of the monitoring indicators, this paper uses a cloud model to perform real-time data exchanges between the terminal and the cloud, and establishes an intelligent monitoring service system for the depression of college students to better understand, monitor, judge and warn about their depression status. The purpose is to eventually provide college students and college administration departments with intelligent knowledge services like depression monitoring and early warning through the system.

This paper advocates the use of an intelligent cloud model to improve the mental health services for college students and designs a public service platform based on the cloud model. This model performs real-time health data exchanges between the terminal and the cloud, and ultimately pushes related health information through websites or apps to users.

\section{System Design}

\subsection{Investigation of the depression monitoring and management system in college students}

In order to investigate the current situation of the depression monitoring and management system for college students, semi-structured interviews were conducted with system R\&D Engineers, college students, student administration departments and psychological experts. Table 1 shows the specific situation.

As can be seen, there are some deficiencies in the current depression monitoring and management system for college students, and in the future, it is necessary to work more on the system intelligence and the mental health services for depression. Currently, both college students and college administration departments are in need of an intelligent knowledge service system that can detect and monitor the mental health of college students dynamically for a long time, screen and warn students with depression tendencies and provide online psychological counseling services and communicate knowledge on depression and mental health. 
Table 1. Depression monitoring and management system for college students

\begin{tabular}{|c|c|c|}
\hline Object & $\begin{array}{c}\text { Research Di- } \\
\text { mension }\end{array}$ & Situation Description \\
\hline $\begin{array}{l}\text { System R\&D } \\
\text { Engineers }\end{array}$ & System design & $\begin{array}{l}\text { The intelligent system generally takes the data acquisition layer as the } \\
\text { basis, the knowledge layer as the data knowledge base, and the intelli- } \\
\text { gent processing layer as the core. } \\
\text { The ultimate goal of system design is to realize system intelligence and } \\
\text { provide users with convenient and effective services. } \\
\text { Portable health data acquisition equipment is the development direction } \\
\text { for system data acquisition. }\end{array}$ \\
\hline College Student & $\begin{array}{l}\text { Mental health } \\
\text { services for } \\
\text { depression }\end{array}$ & $\begin{array}{l}\text { College students are prone to depression, but it is difficult for them to } \\
\text { seek effective mental health intervention services. } \\
\text { It is difficult for college students to understand the changes in their } \\
\text { mental health as depression cannot be visually shown. } \\
\text { More and more college students begin to pay attention to their depres- } \\
\text { sion status, hoping to find mental health information about depression } \\
\text { on the Internet. } \\
\text { Online video course learning is one of the best ways for college stu- } \\
\text { dents to improve their mental health and ease depression. } \\
\text { Online counseling is the most recognized and accepted mental health } \\
\text { service for college students with depression and it is believed that it can } \\
\text { improve student's depression status in a timely and effective manner. }\end{array}$ \\
\hline $\begin{array}{l}\text { College Student } \\
\text { Administration } \\
\text { Department }\end{array}$ & $\begin{array}{l}\text { Mental health } \\
\text { management } \\
\text { system for } \\
\text { depression }\end{array}$ & $\begin{array}{l}\text { College students are prone to depression, and it is difficult for the } \\
\text { student Administration Department to timely detect students with } \\
\text { depression tendency or depressed students. } \\
\text { At present, the mental health management system for depression is not } \\
\text { intelligent enough to independently identify students with potential } \\
\text { problems and dynamically detect and monitor the changes in students' } \\
\text { depression. } \\
\text { The early warning and monitoring of depression play an important role } \\
\text { in the management of depression. } \\
\text { It is an important function of the system to precisely push mental health } \\
\text { services to users, so that students can get targeted services as soon as } \\
\text { possible and their depression status can be controlled. }\end{array}$ \\
\hline $\begin{array}{l}\text { Psychological } \\
\text { Experts }\end{array}$ & $\begin{array}{l}\text { Objective moni- } \\
\text { toring indicators } \\
\text { for depression }\end{array}$ & $\begin{array}{l}\text { Sleeping, exercise and heart rate are three objective indicators for } \\
\text { depression detection, monitoring and early warning. } \\
\text { Students with poor sleep quality are more likely to suffer from depres- } \\
\text { sion [9-10]. } \\
\text { Sudden increase or decrease of sleep for more than } 2 \text { hours, which lasts } \\
\text { for more than one week, can be used as an indicator of depression } \\
\text { tendency [11-12]. } \\
\text { Physical activity of students was associated with the incidence of } \\
\text { depression [13]. } \\
\text { Students who suddenly reduce physical activity over time are more } \\
\text { likely to be depressed [14]. } \\
\text { The onset of depression will affect the change of the HRV index [15]. } \\
\text { The decrease of HRV can be used as a reference to evaluate the severity } \\
\text { of depression [16]. }\end{array}$ \\
\hline
\end{tabular}

\subsection{Overall architecture design}

Based on the above research, this paper establishes an intelligent depression monitoring system model for college students., which collects the mental health data of college students, conducts monitoring and analysis of depression data, identify students who have depression tendencies or suffer from depression and give them early 
warnings and feedbacks and further provide appropriate mental health intervention services to users by using the big data and the cloud computing technology. Through this system, the college student administration departments will be able to monitor the mental health of students and effectively control and manage their mental status. The overall system design is shown in Figure 1.

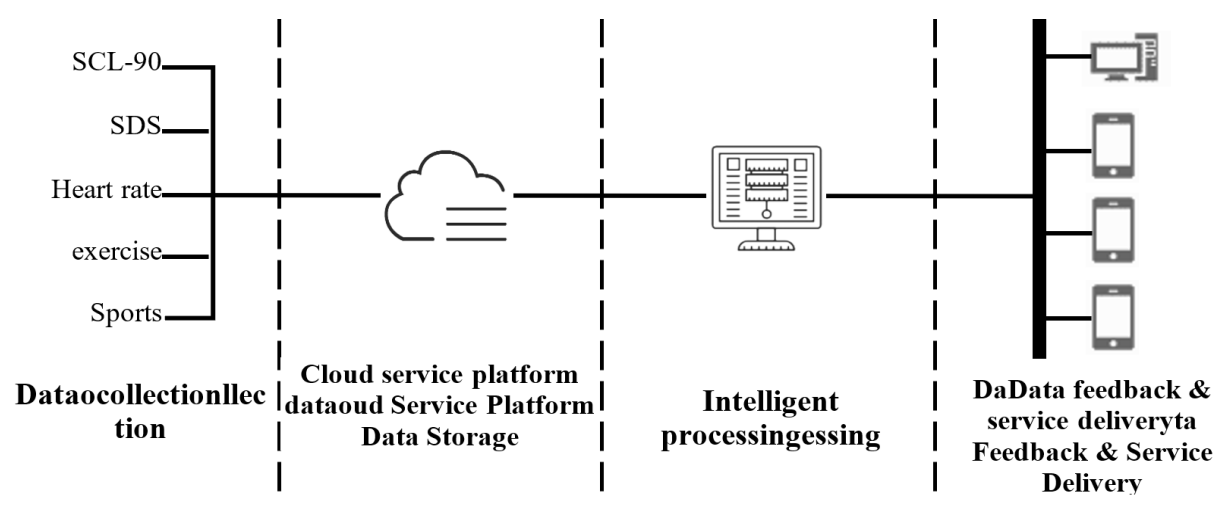

Fig. 1. General design of intelligent depression monitoring system for college students

The mental health data of college students were collected from three objective indicators of the symptom self-rating scale (SCL-90), the self-rating scale (SDS) and MMLD. The collected data are encrypted and uploaded to the cloud service platform for storage, and then sent to the data processing center for analysis, calculation and processing. In order to facilitate the operation of data, the data processing algorithm is used to complete the data analysis and collation, forming special data results. The results are displayed to the users in the browsing interface of the computer or mobile phone, and then the users can choose relevant mental health services.

\subsection{System architecture design}

The system is divided into five layers: user layer, data acquisition layer, knowledge layer, intelligent processing layer and service layer. The specific architecture diagram is shown in Figure 2. 


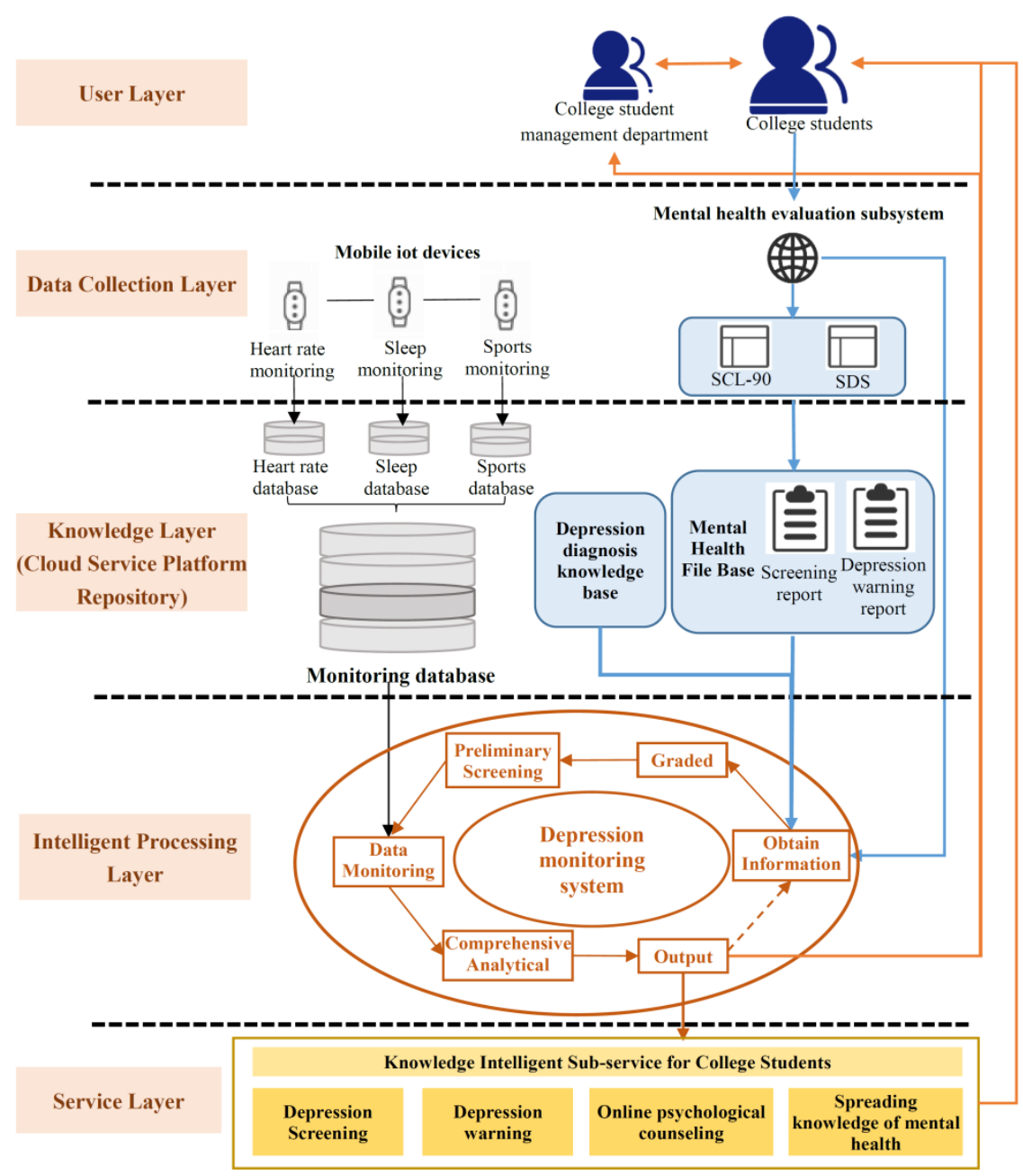

Fig. 2. System architecture diagram

User layer: For the sake of meeting the needs of college administrators in management of the mental health of college students with depression, an intelligent knowledge service system based on depression monitoring is developed for college students, college administration departments and administrators.

Data acquisition layer: After review of extensive literatures related to the health management of college students with depression, it is found that the three indicatorssleeping, exercise and heart rate-are closely related to the depression of college students. It is demonstrated by psychological experts in Table 1 that it is feasible to use MMLD to collect data and information, dynamically monitor and analyze the changes in the depression status of college students, give early warning in a timely manner and provide individualized and chain-based mental health services for depression. 
On the ground of the assessment results of experts, the data acquisition layer uses MMLD to collect three types of objective data, including heart rate, sleeping and exercise. The mental health self-assessment data of college students were collected based on the SCL-90 and SDS in the mental health assessment subsystem.

Knowledge layer: The knowledge layer is the database of the intelligent knowledge service system for depression monitoring of college students, which is stored in the cloud, also known as the cloud service platform. This layer consists of a monitoring database composed of the data collected by the MMLD, a depression diagnosis knowledge base which is the core content of the data layer, made up of the health data of people with depression, mainly including sleeping, exercise, heart rate and other objective data and basic information, such as age, gender, history of depression and the mental health intervention services received, so as to provide knowledge basis for the intelligent depression detection system and mental health archives primarily consisted of the multi-dimensional mental health information collected by SCL-90 and SDS, as well as the screening reports and depression warning reports.

Intelligent processing layer: This layer is the core of system operation. On the one hand, it receives information resources from the system resource layer, and carries out preliminary screening and comprehensive analysis. On the other hand, it can output the screening and warning results, generate screening reports and depression warning reports automatically, and make updates in the mental health archives, to complete the individual mental health archives of college students. Both administrators and college students have access to the screening reports and depression warning reports in the system.

Service layer: This layer chiefly provides users with intelligent knowledge services for depression monitoring:

1. Intelligent depression screening knowledge sub-service for college students

2. Intelligent depression warning knowledge sub-service for college students

3. Intelligent online psychological counseling knowledge sub-service for college students

4. Intelligent mental health communication knowledge sub-service for college students.

\section{$3 \quad$ Intelligent Cloud Services}

With the rapid development of network technology, the application of cloud service has become more important and common. Cloud computing [17-22] is a new internet-based computing technology combining the distributed processing technology, the parallel processing technology and the grid computing technology. Users do not have to care about the internal structure of their services and the way the real services are formed, and the services so formed are called as cloud services. The cloud services architecture has been studied, including server clusters, DB clusters (Cloud Storage) and template engines. Data transmitted from each analysis and processing task will be done on server clusters. Its detailed architecture is presented in Figure 3. 


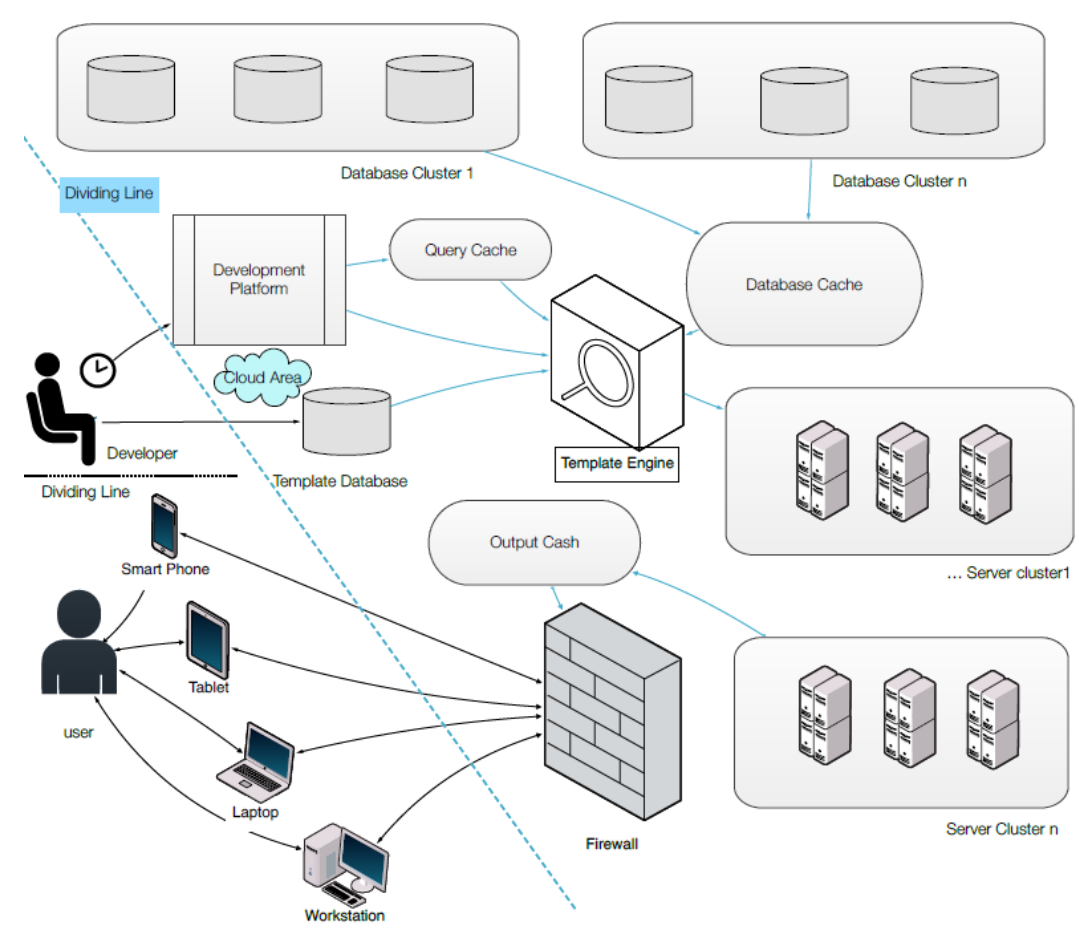

Fig. 3. Cloud services architecture

With the social development, IT has become an important part of public service work. In recent years, the innovation of internet technology has brought the development of new service infrastructures. Information construction will eventually become the next vital task for student administration in colleges.

Based on the previous research summary and interview survey, an intelligent knowledge service system for monitoring depression of college students is developed and designed. The system consists of four sub-services, including: intelligent depression screening knowledge sub-service for college students, intelligent depression warning knowledge sub-service for college students, intelligent online psychological counseling knowledge sub-service for college students and intelligent mental health communication knowledge sub-service for college students.

\subsection{Intelligent depression screening knowledge sub-service for college students}

College students are the target users of the system, and college student administration departments are the administrators of the system. First, the system uses the depression evaluation scale to preliminarily evaluate college students' mental health conditions and select the students with depression tendencies. These students are systematically monitored for health conditions by wearing MMLD through activities such as exercise, heart rate and sleeping Through intelligent knowledge calculation in 
the standardized medical record database, depressed patients can be identified. In this system, those with one abnormal indicator are identified as Class I depression patients, and those with two abnormal indicators as Class II ones.

Student oriented service : Based on its analysis and processing functions, the platform can provide the following services:

- Through completion of the SCL-90 and SDS in the system, the platform will automatically push the assessment reports to college students

- The platform analyzes the information of the scale in a standardized way and submits it to the cloud. User data are stored in the cloud and delivered to the users' intelligent terminal through the node server in two ways:

- If the results of the initial screening against the scale are normal, the data of the student will be stored in the individual's health file in the system for future analysis of mental health conditions

- If the results of the initial screening against the scale are abnormal, the system will automatically mark the student, and recommend the student wearing the MMLD, and at the same time push the basic information and the preliminary screening results of the depression tendency scale to the student's administrator. Administrators provide such students with health devices to collect information about their information about exercise, sleeping and heart rate

- The system acquires data in a timely and accurate manner, and carries out real-time and dynamic monitoring of college students' mental health. If the monitoring results are abnormal, the system will push information to students, their administrators, and the relevant administration departments, to provide relevant services

- Students with abnormal monitoring results will return to the system for further monitoring and push relevant information to the student administrators and student administration departments.

College student administration department-oriented service: The customers of the cloud service platform are mainly the student administration departments of various universities. The mental health data of college students are dynamically uploaded to the platform. After the intelligent system summarizes and analyzes the data, the platform will provide the following services. a) statistical analysis service for mental health data of students which can reflect the overall changes in the mental health of students, so that the student administration departments can formulate more reasonable education programs for students based on the statistical analysis results. b) With the help of real-time monitoring of mental health status, which is beneficial to understand the situation of students, notifications of the monitoring results can be pushed to different persons according to different evaluation levels

\subsection{Intelligent depression warning knowledge sub-service of for college students}

Through the analysis of scale information, the system marks the students whose results exceed the threshold and for whom at least one of the three indicators-heart rate, 
sleeping and exercise-changes abnormally within a period of time. That is when the intelligent depression warning knowledge service is triggered in the system, which sends different types of early warning results of this group (depression assessment and screening report and depression early warning report) to the students themselves, the college student administration departments or the psychological counselors. For Class I depression, the results will be sent to the students and the student administration departments, and for Class II depression, in addition to above, the system will recommend the most suitable psychological counselors for the students through intelligent computing.

Screening and early warning reports: Any college student who is marked with Class I or II depression by the system will receive a personal depression screening report, which will analyze the individual's mental health according to the system data so that college students will understand their own mental health status and choose appropriate services actively. Meanwhile, the screening report is fed back to the college student administration departments, in order to grasp the mental health of each college student in a timely manner and take effective intervention measures. When a student selects a mental health counselor/psychiatrist, it is deemed that he or she agrees to authorize all health information including personal mental health records to the mental health counselor/psychiatrist. After counseling or treatment, each student needs to update, supplement and improve the screening and warning report in the mental health record in a timely manner.

Early warning statistics list: This function is open only to the college student administration departments; in other words, only the administrator has access to the early warning statistical list, which shows the name, gender, grade, class, major, warning type, detection time and other information of the marked college students, as shown in Table 2. The administrator can click on the specific case in the list to view the detailed report. According to the information obtained by the current system, the statistics are displayed by early warning types and levels.

Table 2. List of depression warning statistics for college students

\begin{tabular}{|l|l|l|l|}
\hline \multicolumn{1}{|c|}{ Name } & \multicolumn{1}{c|}{ Type } & \multicolumn{1}{c|}{ Constraint Condition } & \multicolumn{1}{c|}{ Explanation } \\
\hline TableA_Index & Int & No empty & Number \\
\hline TableA_Num & Char(20) & No empty, No repeat & Student Id, Primary Key. \\
\hline TableA_Name & Char(20) & No empty & Name \\
\hline TableA_Sex & Char(2) & No empty & Gender \\
\hline TableA_Grade & Char(20) & No empty & Grade \\
\hline TableA_Class & Char(20) & No empty & Class \\
\hline TableA_Major & Char(50) & No empty & Professional \\
\hline TableA_Type & Char(100) & No empty & Depression Type \\
\hline TableA_DTime & DateTime & No empty & Testing Time \\
\hline
\end{tabular}




\subsection{Intelligent online psychological counseling knowledge sub-service for college students}

The platform cooperates with experienced psychological counselors in colleges and integrates high-quality mental health expert resources into a database of psychological counselors, and provides online counseling services for users. Users of the system can, on the one hand, independently select and make appointments with psychological counselors through the system to receive online counseling services. On the other hand, the system can, according to the specific situation of students, intelligently match the most suitable psychological counselors for students to achieve the optimal effect.

After counseling, the psychological counselor shall fill in the structured counseling record with the counseling result, and transmit it to the student mental health file on the cloud service platform through the system. The data should be updated constantly so that the college student administrators can manage and monitor the depression developments of the students. If it is found that the students are in serious psychological condition and need to receive more professional psychological therapies, the counselor shall submit relevant information in a timely manner to the students and also the college student administration departments.

Meanwhile, the platform cooperates with the mental health departments of major hospitals so that it can transfer patients there for further treatment. According to the information uploaded by counselors, the platform can intelligently match psychiatrists and provide offline appointment services. After the psychiatrist treats users, the feedbacks of the treatment process will be added as updates to the student's mental health file on the cloud service platform in a timely and comprehensive manner. After the treatment, the information of the student will be automatically uploaded to the mental health file in the system, and the system will provide him or her with further intelligent services as mentioned in 3.1, 3.2 and 3.4.

\subsection{Intelligent mental health communication knowledge sub-service for college students}

The existing mental health education in colleges mainly focuses on teaching, and the knowledge is limited in the region. Therefore, the platform needs to integrate external high-quality expert teaching resources to establish a knowledge base for mental health MOOCs. On the one hand, students can independently choose the MOOCs they are interested in in the system for learning. On the other hand, the platform also intelligently identifies the most suitable type of MOOCs and accurately push the learning content based on real-time monitoring of the students. At the same time, the platform is in contact with psychological counselors in colleges and universities and psychological experts in hospitals to provide them with MOOC learning opportunities, improve the knowledge structures and abilities of psychological experts, and realize the service ability of 3.3 better. 
This mode of building knowledge with external experts provides users of the system with learning opportunities. This service is a dynamic process of knowledge learning, which mainly includes:

- Professional growth and learning of psychological counselors

- Technical training of psychological experts

- Mental health knowledge base service for college students. In this system, users can learn MOOCs according to individual needs.

\section{$4 \quad$ Function and Algorithm Implementation}

\subsection{Intelligent depression screening module}

System screening is to evaluate the depression of students and give ratings based on the scales completed by students against the depressive symptom knowledge base and the clinical diagnostic rules. The students with the scores exceeding the thresholds will be marked and considered as monitoring targets. They will need to wear MMLDs for further monitoring and judgment on their mental health conditions.

\subsection{Intelligent early depression warning module}

There is subjectivity in the systematic scale screening of potential depressed patients. Therefore, this paper introduces objective indicators such as sleeping, exercise and heart rate to analyze the mental health status of students comprehensively and realize the intelligent early warning of students about depression, which is realized by the text mining method.

In this paper, XML is selected as the representation of knowledge in this paper. The text-based closeness between Kdx (sleeping, exercise and heart rate monitoring indicators) and Kdy (knowledge base of depression diagnosis) is calculated through the text mining method. Through the following formula, the similarity between Kdx and Kdy is obtained:

$$
\operatorname{Osc}_{\text {text }}(K d x, K d y)=\cos (K d x, K d y)=\frac{\sum_{i} K d x_{i} K d y_{i}}{\sqrt{\sum_{j} K d x_{j}^{2} \sum_{i} K d y_{i}^{2}}}
$$

According to the knowledge similarity, the system can automatically match one or more of the indicators (sleeping, exercise and heart rate) with the depression warning knowledge base, and send the warning signals to students.

\subsection{Intelligent depression service module}

Based on the intelligent early warning module, the system provides intelligent knowledge push service, through the intelligent calculation of the closeness between users and knowledge. 
Matrix design: The number of times, for which the knowledge is used by query in the system, is recorded in detail. If two pieces of knowledge are often used by the same user, the closeness of the two pieces of knowledge will be smaller. In this paper, the following matrix is designed to record the information of knowledge used. In the formula, num $_{\text {use }}$ is an integer, used to represent the number of times for which the knowledge $k d_{i}$ is used by user $P_{i}$ through query.

\begin{tabular}{|c|c|c|c|c|}
\hline & $P_{1}$ & $P_{2}$ & $P_{3}$ & $P_{4}$ \\
\hline & rnum $_{u}$ & num $_{\text {use } 12}$ & num $_{\text {use } 13}$ & um \\
\hline $\begin{array}{l}d_{2} \\
d_{3}\end{array}$ & & $\begin{array}{l}\text { num }_{\text {use } 22} \\
\text { num }_{\text {use } 32}\end{array}$ & $\begin{array}{l}\text { num }_{\text {use } 23} \\
\text { num }_{\text {use } 33}\end{array}$ & \\
\hline & num $_{\text {use } 41}$ & num $_{\text {use } 42}$ & num $_{\text {use } 43}$ & num $_{\text {use }}$ \\
\hline
\end{tabular}

Closeness intelligent computing: In this paper, knowledge push is realized by intelligent calculation of knowledge closeness. The closeness between user $U$ and the knowledge base for depression diagnosis is calculated from the user's point of view using the following formula.

$$
O s c_{u s e(k d \& U)}\left(k d_{a}, U_{d}\right)=\frac{\sum_{t} O s c_{u s e}\left(k d_{a}, k d_{t}\right)}{n_{k d}}
$$

The system records students' use and query of the depression diagnosis knowledge base, and determines which piece of knowledge is more suitable for a certain scenario according to the historical usage and users' feedbacks, and also actively carries out automatic matching between the monitoring indicators (sleeping, exercise, and heart rate), the depression diagnostic knowledge base and the corresponding intervention services (online psychological counseling, mental health communication and other mental health intervention services) so that intervention services can be pushed appropriately.

\section{Conclusion}

This paper proposes an intelligent knowledge service system for depression monitoring of college students. In which a knowledge base for depression diagnosis, a monitoring database and mental health archives are established. All data resources and service information are stored in the cloud platform. College students fill in the SCL-90 and SDS forms on this platform for initial screening of depression tendency. Those who are initially screened out wear MMLDs for intelligent monitoring of sleeping, exercise and heart rate. The platform feeds back the results in a timely manner, and provides the intelligent depression screening sub-service, intelligent depression warning sub-service, intelligent online psychological counseling sub-service and intelligent psychological health communication sub-service for college students. In this process, MMLDs continuously monitor the mental health of college students with depression. This long-term, dynamic and two-way monitoring model will have a significantly positive impact on the prevention, monitoring and management of mental health in the future. 


\section{References}

[1] Liu, Y., Zhang, N., Bao, G.Y., Huang, Y.B., Ji, B.Y., Wu, Y.L., Liu, C.X., Li, G.Y. (2019). Predictors of depressive symptoms in college students: A systematic review and meta-analysis of cohort studies. Journal of Affective Disorders, 244: 196-208. https://doi.org/10.1016/j.jad.2018.10.084. 10.084

[2] Eapen, V., Črnčec, R. (2012). Strategies and challenges in the management of adolescent depression. Curr. Opin. Psychiatry, 25(1): 7-13. https://doi.org/10.1097/yco.0b013e32834de3bd

[3] Fava, G.A., Grandi, S., Canestrari, R., Molnar, G. (1990). Prodromal symptoms in primary major depressive disorder. Journal of Affective Disorders, 19(2): 149-152. https://doi.org/10.1016/0165-0327(90)90020-9

[4] Manber, R., Chambers, A.S. (2009). Insomnia and depression: A multifaceted interplay. Current Psychiatry Reports, 11: 437-442. https://doi.org/10.1007/s11920-009-0066-1

[5] Motivala S.J., Irwin M.R. (2007). Sleep and immunity: cytokine pathways linking sleep and health outcomes. Current Directions in Psychological Science, 16(1): 21-25. https://dor.org/10.1111/j.1467-8721.2007.00468.x

[6] Slawson, D. (2005). Aerobic exercise effective for mild to moderate depression. American Family Physician, 71(9): 1769-1770. https://doi.org/10.1136/bmj.330.7494.0-f

[7] Rothon, C., Edwards, P., Bhui, K., Viner, R.M., Taylor, S., Stansfeld, S.A. (2010). Physical activity and depressive symptoms in adolescents: a prospective study. Bmc Medicine, 8(1): 32-40. https://doi.org/10.1186/1741-7015-8-32

[8] Nahshoni, E, Aravot, D., Aizenbegr, D. (2004). Heart rate variability in patients with major depression. Psycho maties, 45: 129-134. https://doi.org/10.1176/appi.psy.45.2.129

[9] Sözeri-Varma, G., Karadağ, F. (2012). The Biological Effects of Psychotherapy in Major Depressive Disorders: A Review of Neuroimaging Studied. Psychology, 3(10): 857-863. https://doi.org/10.4236/psych.2012.310129

[10] Kemp, A.H., Quintana, D.S., Gray, M.A., Felmingham, K.L., Brown, K., Gatt, J.M. (2010). Impact of depression and antidepressant treatment on heart rate variability: a review and meta-analysis. Biological Psychiatry, 67(11): 1067-1074. https://doi.org/10.1016/j.biopsych.2009.12.012

[11] Tsuno, N., Besset, A., Ritchie, K. (2005).Sleep and depression. Clin Psychiatr, 66(12): 5469. https://doi.org/10.4088/jcp.v66n1008

[12] Quevedo-Blasco, R., Zych, I., Buela-Casal, G. (2014). Sleep apnea through journal articles included in the web of science in the first decade of the 21stcentury. Revista Iberoamericana de Psicologíay Salud, 5: 39-53. https://doi.org/10.1161/STROKEAHA.112.657809

[13] Lin, S.Z. (2008). College students depressive and Leisure Sports. Journal of Nanjing Institute of physical Education (Social Science Edition), 22(2): 124-126. https://doi.org/10.15877/j.cnki.nsic.2008.02.023

[14] Taliaferro, L.A., Rienzo, B.A., Pigg, R., Morgan, J.R., Miller, M.D., Dodd, V.J. (2009). Associations between physical activity and reduced rates of hopelessness, depression, and suicidal behavior among college students. Journal of American College Health, 57(4): 427435. https://doi.org/10.3200/JACH.57.4.427-436

[15] Bie, H.X., Li, J. (2010). Application of Heart Rate Variability Analysis in Psychiatric Diseases. Medical Recapitulate, 16(16): 2441-2444. https://doi.org/10.3969/j.issn.10062084.2010.16.015

[16] Hughes, J.W., Stoney, C.M. (2000). Depressed mood is related to high-frequency heart rate variability during stressors. Psychosom Med, 62(6): 796-803.

https://doi.org/10.1097/00006842-200011000-00009 
[17] Naresh, A., Syed, S.A., Prasad, B.V.V.S. (2018). Mining user actions with fuzzy related data security conviction in cloud computing. Ingénierie des Systèmes d'Information, 23(5): 201-212. https://doi.org/10.3166/ISI.23.5.201-212

[18] Sen, M., Sasmita, S.C. (2017). Security and privacy issues for cloud computing and its challenges. Review of Computer Engineering Studies, 4(2): 62-66. https://doi.org/10.18280/rces.040204

[19] Alabbadi, M.M. (2011). Cloud Computing for Education and Learning: Education and Learning as a Service (ELaaS). 14th International Conference on Interactive Collaborative Learing (ICL), 589-594. https://doi.org/10.1109/icl.2011.6059655

[20] Yang, X.Q., Deng, Y.J. (2010). Exploration of Cloud Computing Technologies for Geographic Information Services. 18th International Conference on Geoinformatics, 1-5. https://doi.org/10.1109/geoinformatics.2010.5567515

[21] Singamaneni, K.K., Naidu, P.S. (2018). Secure key management in cloud environment using quantum cryptography. Ingénierie des Systèmes d'Information, 23(5): 213-222. https://doi.org/10.3166/ISI.23.5.213-222

[22] Gupta, A., Bandyopadhyay, S., Thakur, S.S. (2017). Cloud computing: its characteristics, security issues and challenges. Review of Computer Engineering Studies, 4(2): 76-81. https://doi.org/10.18280/rces.040207

\section{$7 \quad$ Authors}

Huina Yu, Guihong Zhang, Jiali Liu, and Kai Li are with Zhejiang Chinese Medical University, Hangzhou, Zhejiang, China

Article submitted 2019-04-19. Resubmitted 2019-06-03. Final acceptance 2019-06-04. Final version published as submitted by the authors. 